\title{
Seasonal cycles of the TBE and Lyme borreliosis vector Ixodes ricinus modelled with time-lagged and interval- averaged predictors
}

\author{
Katharina Brugger $^{1}\left(\mathbb{D} \cdot\right.$ Melanie Walter $^{1} \cdot$ Lidia Chitimia-Dobler $^{2,3}$ • \\ Gerhard Dobler $^{2,3,4} \cdot$ Franz Rubel $^{1}$
}

Received: 24 July 2017/ Accepted: 17 November 2017/Published online: 27 November 2017

(C) The Author(s) 2017. This article is an open access publication

\begin{abstract}
Ticks of the species Ixodes ricinus (L.) are the major vectors for tick-borne diseases in Europe. The aim of this study was to quantify the influence of environmental variables on the seasonal cycle of questing I. ricinus. Therefore, an 8-year time series of nymphal $I$. ricinus flagged at monthly intervals in Haselmühl (Germany) was compiled. For the first time, cross correlation maps were applied to identify optimal associations between observed nymphal I. ricinus densities and time-lagged as well as temporal averaged explanatory variables. To prove the explanatory power of these associations, two Poisson regression models were generated. The first model simulates the ticks of the entire time series flagged per $100 \mathrm{~m}^{2}$, the second model the mean seasonal cycle. Explanatory variables comprise the temperature of the flagging month, the relative humidity averaged from the flagging month and 1 month prior to flagging, the temperature averaged over 4-6 months prior to the flagging event and the hunting statistics of the European hare from the preceding year. The first model explains $65 \%$ of the monthly tick variance and results in a root mean square error (RMSE) of 17 ticks per $100 \mathrm{~m}^{2}$. The second model explains 96\% of the tick variance. Again, the accuracy is expressed by the RMSE, which is 5 ticks per $100 \mathrm{~m}^{2}$. As a major result, this study demonstrates that tick densities are higher correlated with time-lagged and temporal averaged variables than with contemporaneous explanatory variables, resulting in a better model performance.
\end{abstract}

Gerhard Dobler and Franz Rubel have contributed equally to this article.

Katharina Brugger

katharina.brugger@vetmeduni.ac.at

1 Institute for Veterinary Public Health, University of Veterinary Medicine Vienna, Veterinärplatz 1, 1210 Vienna, Austria

2 Bundeswehr Institute of Microbiology, Neuherbergstraße 11, 80937 Munich, Germany

3 German Center of Infection Research (DZIF) Partner Site Munich, Munich, Germany

4 Parasitology Unit, University of Hohenheim, Emil-Wolff-Straße 34, 70593 Stuttgart, Germany 
Keywords Castor bean tick · Cross-correlation map · Climate $\cdot$ Hunting statistics · Tick-borne diseases

\section{Introduction}

It is undeniable that ticks and their ability to transmit medically relevant pathogens play an important role for public health. The most important examples are the tick-borne encephalitis (TBE) virus or Borrelia burgdorferi sensu lato, the complex of bacteria causing Lyme borreliosis (LB). Reviews on TBE and LB concerning the study region Central Europe (Germany) have recently been published on the epidemiology and distribution of TBE (Dobler et al. 2012), the progress in TBE research (Kunze and The ISWTBE 2016) and LB in general (Stanek et al. 2012). To contribute to an adequate TBE and LB risk assessment, which should incorporate the phenology of the vectors involved (Norman et al. 2016), an enhanced method to determine variables explaining the seasonal cycles of ticks is introduced. The focus is on the main vector Ixodes (I.) ricinus, which is widely distributed in Germany (Rubel et al. 2014).

Brugger et al. (2016) compiled a dataset of 69 German sites from which monthly $I$. ricinus time series were collected. However, most of these time series are only 1-2 years long and so unsuitable to depict inter-annual tick fluctuations. The longest time series in Haselmühl (Germany) lasting eight consecutive years without data gaps, was used in this study. As all the other tick time series compiled by Brugger et al. (2016), the number of ticks (abundance) was related to the same flagging area of $100 \mathrm{~m}^{2}$. Thus, ticks were given as densities in units $1 / 100 \mathrm{~m}^{2}$. To quantify the seasonal and inter-seasonal activity of ticks usually climatic variables as temperature or precipitation were used (e.g. Cat et al. 2017; Schulz et al. 2014). Contrary to the monthly tick time series, such variables are observed on a regular base (previously several times per day, meanwhile every minute) under defined standards (World Meteorological Organization 2008). Some time-series last over more than two centuries, e.g. in Germany the stations Berlin or Hohenpeißenberg.

So far the majority of studies used climatic variables on the sampling day to explain influences on the seasonal tick density (Daniel et al. 2015; Berger et al. 2014). In some cases, a possible time-lagged association of climate variables up to 8 days prior to the sampling event was considered (Barandika et al. 2006; Kiewra et al. 2014; Li et al. 2012). However, in all studies, the influence of these short time lags was determined not to be significant. Only Kazimírová et al. (2016) reported a negative correlation between nymphal density and the mean saturation deficit of the preceding 2 months. More frequently temporal accumulated or averaged climate variables have been used to statistically explain tick seasonality (Perret et al. 2000; Alonso-Carné et al. 2016; Osipova et al. 2017). Alternatively, the effect of the winter conditions on the subsequent tick season was conceived by defining temperature or relative humidity thresholds (Dautel et al. 2008; Vollack et al. 2017).

Here, an enhanced method of the classical correlation analysis, frequently used to determine the influence of environmental variables, is applied. With these cross correlation maps (CCMs), optimal associations between ticks sampled during a specific flagging event and time-lagged as well as interval-averaged environmental variables were identified. Initially developed for mosquitoes of the genus Aedes spp. (Curriero et al. 2005; Shone et al. 2006), this method has also been applied for Culex spp. (Walsh et al. 2008; Chuang et al. 2012; Lebl et al. 2013; Lockaby et al. 2016; Groen et al. 2017), biting midges such as Culicoides spp. (Brugger and Rubel 2013; Diarra et al. 2015), and stable flies such as 
Stomoxys calcitrans (Taylor et al. 2007; Taylor and Berkebile 2011). Recently, CCMs have also been used to explain the seasonal dynamics of dengue (Stoddard et al. 2014) and to detect abortive diseases in cattle (Bronner et al. 2015).

Here, this method is applied for the first time to ticks (nymphal I. ricinus). As the life cycle of I. ricinus comprises four life stages (egg, larva, nymph, and adult) and lasts up to several years (Gray et al. 2016), time-lagged influences should be considered for a comprehensive analysis of tick dynamics. Within this usually 3- to 4-year period, key processes determining the tick dynamics such as development (rate and duration, emergence), diapause (survival, inactivity) and questing (activity, ability to find host, survival) are affected by environmental variables (Ostfeld and Brunner 2015). This study aims to quantify the time-lagged and interval-averaged influence of environmental variables on tick density and, secondly, to simulate the seasonal and inter-annual density fluctuations for a disease risk assessment.

\section{Materials and methods}

\section{Study site and tick flagging}

The site Haselmühl is one of the most intensively studied natural foci of tick-borne encephalitis (TBE) in Germany (Weidmann et al. 2013). This rural area in the administrative district of Amberg-Sulzbach is around $60 \mathrm{~km}$ east of Nuremberg, the second largest city in the German federal state of Bavaria (Fig. 1). The site is located $430 \mathrm{~m}$ above sea level at geographic longitude $11.8819^{\circ} \mathrm{E}$ and latitude $49.4083^{\circ} \mathrm{N}$. The natural focus is characterised by arable fields surrounded by mixed forests with a predominance of pines (Pinus sylvestris) and dense undergrowth.

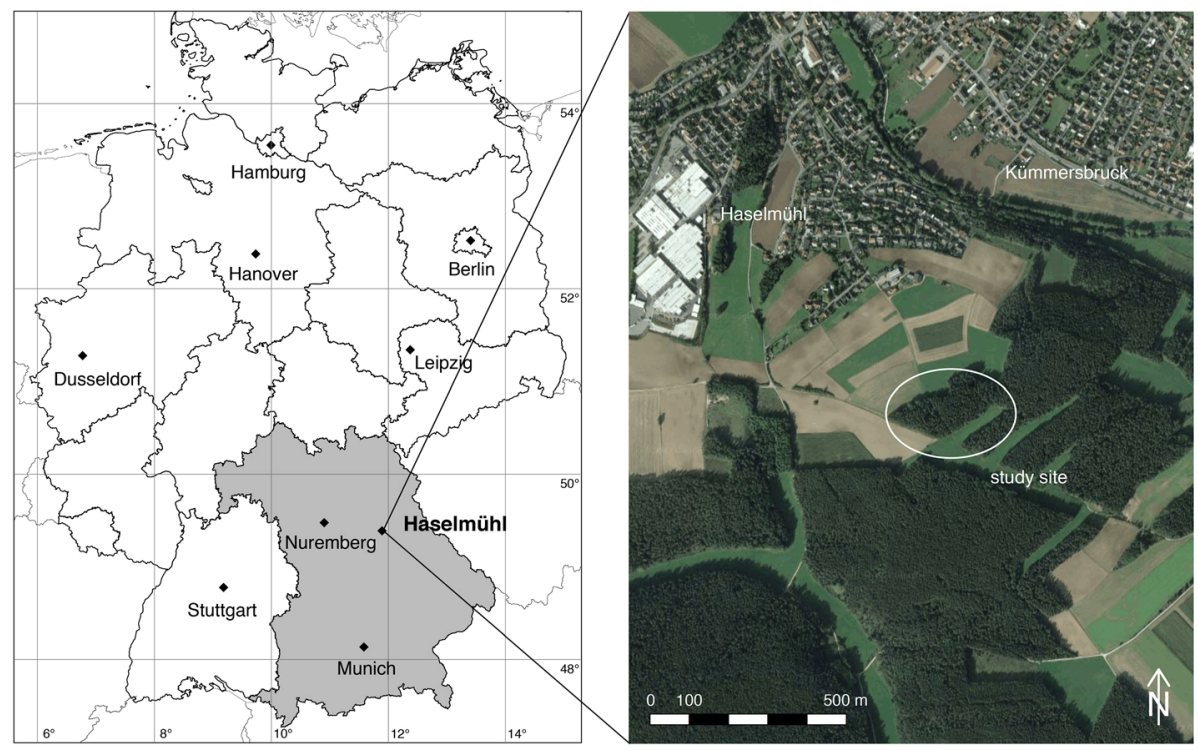

Fig. 1 The flagging site Haselmühl is located in the southeast of Germany in the Bavarian district AmbergSulzbach (left) and is a rural area characterised by arable land, forests, and scattered villages (right) 
Between March 2009 and October 2016, questing I. ricinus (larvae, nymph, adults) were collected at monthly intervals using the flagging method. Ticks were always flagged $2 \mathrm{~h}$ before dawn at the last weekend of the month or, if weather conditions were unsuitable, on the following weekend. A $50 \times 100 \mathrm{~cm}$ flag of cotton cloth was flagged over the low vegetation along a standardised $800 \mathrm{~m}$ trail. The flagged densities were, therefore, the number of questing ticks per $400 \mathrm{~m}^{2}$. The flagging was usually done by two people, each one sampling for $45 \mathrm{~min}$, or by one person sampling for $90 \mathrm{~min}$. The collected ticks were identified under a Zeiss Stemi DV4 microscope using the identification key according to Hillyard (1996).

\section{Explanatory variables}

In this study, climate variables were obtained from the nearest weather station Regensburg-Oberhub (WMO No. 107760) of the German Weather Service (2017). The station is located at the geographic coordinates $12.1021^{\circ} \mathrm{E} / 49.0424^{\circ} \mathrm{N}$ in $365 \mathrm{~m}$ above sea level and around $16 \mathrm{~km}$ away from the flagging site Haselmühl. The latter is characterised by a warm temperate climate with rain throughout the year, classified as $\mathrm{Cfb}$ climate according to Köppen-Geiger (Kottek et al. 2006). This climate is optimal for deciduous and mixed forests (Rubel et al. 2017), which are known for their high I. ricinus density (Boehnke et al. 2015; Brugger et al. 2016). For the period 2008-2016, monthly time series of temperature and relative humidity, were aggregated out of daily measurements. Additionally, 30-year monthly averages (1985-2014) of each variable were calculated.

Another environmental variable affecting tick densities is the availability of suitable hosts. Nymphal ticks mainly feed on small to medium-sized animals, such as rodents, hares or hedgehogs. This is contrary to the behaviour of adults, which prefer to feed on large-sized animals like roe deer (Gray et al. 2016). Although roe deer density is a good site-specific predictor for TBE (Rizzoli et al. 2009), it does not significantly change over time and was, therefore, not suitable for use in the model. However, as no data on the densities and inter-annual changes of rodents were available for Haselmühl, hunting statistics of another host, the European hare (Lepus europaeus), were used. These lagomorphs are known to be both competent reservoir and blood hosts for all tick life-stages, but especially for larvae, in environments lacking rodents (Tälleklint and Jaenson 1993). The Bavarian Ministry of Food, Agriculture and Forestry provides annual hunting statistics for administrative districts via the Wildtierportal Bayern (http://www.wildtierportal. bayern.de). In Bavaria, the official hunting season for hares runs from the 15th October to 31st December.

Tick densities may also vary between years or seasons of the year due to unknown or non-measurable variables. Examples include the availability of suitable hosts for each life stage (Gray 1998), higher mortality rate in the winter months (Gray 1981) or rodent cycles (Mihalca and Sándor 2013). Therefore, the season was included as a categorical variable (classes I-IV). Note that the meteorological season with groups of 3 months based on the annual temperature cycle was used, e.g. meteorological spring includes March, April, and May.

\section{Statistical analysis}

The method of cross correlation maps (CCMs) was applied to determine the environmental variables and their highest correlation with tick densities on defined time lags. As an 
improvement on the ordinary cross correlation, not only the month-to-month correlation between the tick densities and an explanatory variable were obtained, but also time-lagged and interval-averaged correlations by considering a second time lag. The CCM in Fig. 2 (left) shows a maximum correlation between the tick density and, for example, the temperature averaged from time lag 1 (e.g. 13 months) to time lag 2 (e.g. 9 months) prior the flagging event. The CCM method was previously explained in detail by Brugger and Rubel (2013) and the $\mathrm{R}$ source code is provided on the website http://epidemic-modeling. vetmeduni.ac.at/. Based on the findings, a data set comprising environmental variables (e.g. temperature or hunting statistics of hares) was compiled. Finally, two Poisson regression models were developed to simulate the inter-annual tick density of the complete time series (model I) and the mean seasonal cycle (model II). To account for the overdispersion of the data, the standard errors were corrected using a quasi GLM model where the variance is specified by the mean and the dispersion parameter (Zuur et al. 2009). The Akaike information criterion (AIC; Akaike 1974) was used as variable selection criterion. Non-significant variables were removed in a stepwise procedure. The coefficient of determination for generalised linear models $R^{2}$ introduced by Zhang (2017) and the root mean square error (RMSE) were selected as goodness-of-fit measures.

All analyses were conducted with the open-source statistical computing environment $\mathrm{R}$ (R Development Core Team 2017). The package rsq (Zhang 2016) was used for calculating the coefficient of determination $R^{2}$.
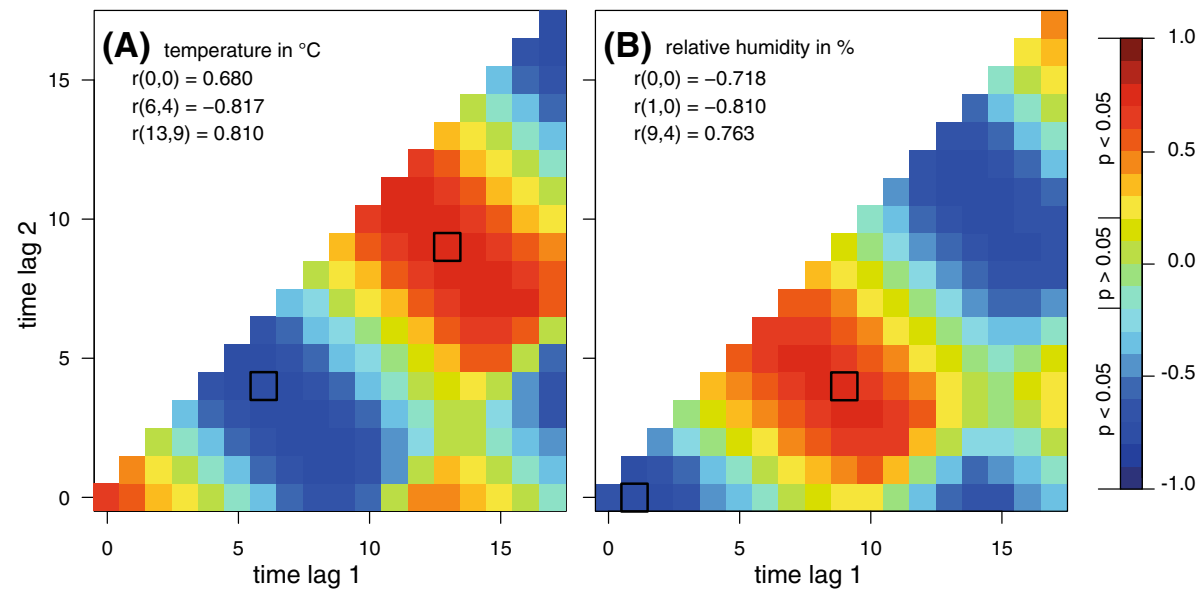

Fig. 2 Cross correlation maps (CCMs) of the monthly time series of nymphal ticks versus both (a) temperature in ${ }^{\circ} \mathrm{C}$ and (b) relative humidity in $\%$. The correlation coefficient for the month of the flagging event $r(0,0)$ as well as the minimum and maximum time-lagged correlation coefficients $r\left(\operatorname{lag}_{1}, \operatorname{lag}_{2}\right)$ are given. The tick density is maximal negatively correlated with the temperature averaged from 6 to 4 months and the relative humidity averaged from 1 to 0 months prior the flagging event. Significance levels depending on the constant sample size of $\mathrm{n}=91$ and the floating correlation coefficient $\mathrm{r}$ indicates that all values $|r| \geq 0.206$ are significant $(p<0.05)$. Period: 2009-2016 


\section{Results}

A total of 473 larvae, 8636 nymphs, and 3819 adult I. ricinus ticks (1897 female, 1922 male) were flagged over 8 years of consecutive sampling (2009-2016). However, as nymphs are the most important stage for pathogen transmission to humans (Gray 1998), only this life stage was considered here. As mentioned above, ticks were collected by flagging an area of $400 \mathrm{~m}^{2}$. To allow for comparison with the more commonly used area of $100 \mathrm{~m}^{2}$, tick numbers were divided by 4 .

The cross-correlation maps revealed that temperature $(\mathrm{T})$ and relative humidity $(\mathrm{rH})$ were highly correlated with nymphal tick densities (Fig. 2). In accordance with the four life stages of $I$. ricinus, a broader time frame of the 18 months preceding the flagging event was considered. For each explanatory variable, the highest positive and negative timelagged and interval-averaged correlations as well as the month-to-month correlations $\mathrm{T}(0,0)$ and $\mathrm{rH}(0,0)$ were determined. For example, the highest negative correlation of $\mathrm{r}(6,4)=-0.817$ was found for ticks versus temperature averaged over 4-6 months prior to the flagging event, while the highest positive correlation of $r(13,9)=0.810$ was found for temperatures averaged from 13 to 9 months prior to flagging.

A set of time series including the monthly temperature and humidity values $T(0,0)$ and $\mathrm{rH}(0,0)$, as well as the time-lagged values identified with the highest positive correlation, $\mathrm{T}(13,9)$ and $\mathrm{rH}(9,4)$, and negative correlation, $\mathrm{T}(6,4)$ and $\mathrm{rH}(1,0)$, was compiled. The set was then incorporated into the regression analysis together with the annual values of the hare hunting statistics and the seasons I-IV as categorical value. Non-significant variables were removed stepwise to select the model with the lowest Akaike information criterion (AIC). The best fitted model included the month-to-month temperature $\mathrm{T}(0,0)$, the mean relative humidity of the actual month and 1 month previously $\mathrm{rH}(1,0)$, the averaged temperature over 4-6 months prior to the flagging event $\mathrm{T}(6,4)$, the hare hunting statistics (hare) shifted by 1 year, and the season as a categorical variable (classes I-IV) as summarized in Table 1. As depicted in Fig. 3, the model simulated the seasonal cycle as well

Table 1 Summary of the Poisson regression models for inter-annual tick density of the complete time series (model I) and the mean seasonal cycle (model II)

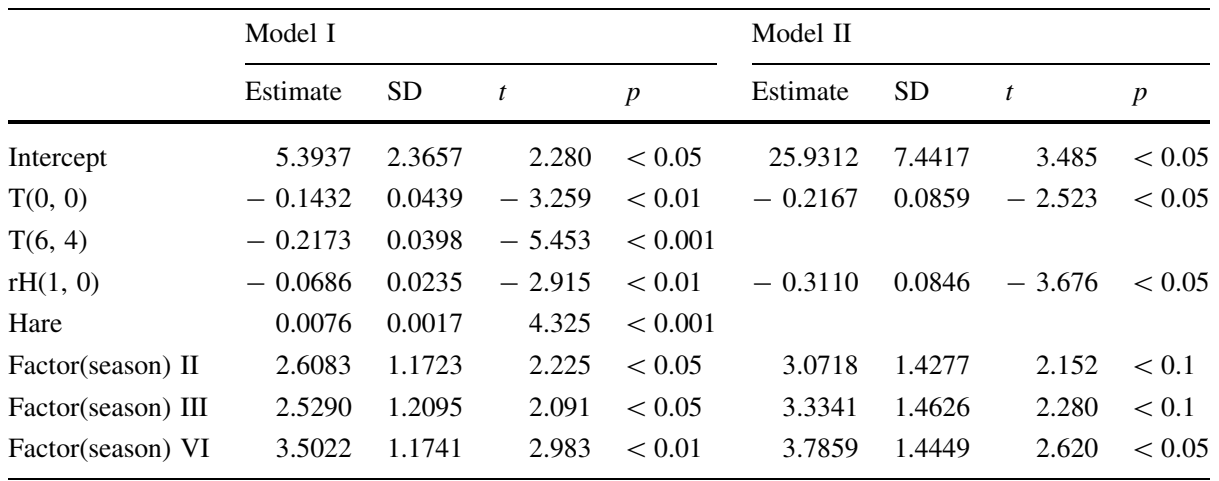

For each explanatory variable, the parameter estimate, the standard error SE, the $t$ value (test statistics), and the $p$ value (significance) are given. Note that factor(season) I is not listed, as it is defined as default. Parameters $\mathrm{T}(6,4)$ and Hare determining the year-to-year variation of the tick density are not needed in model II (mean seasonal cycle) 


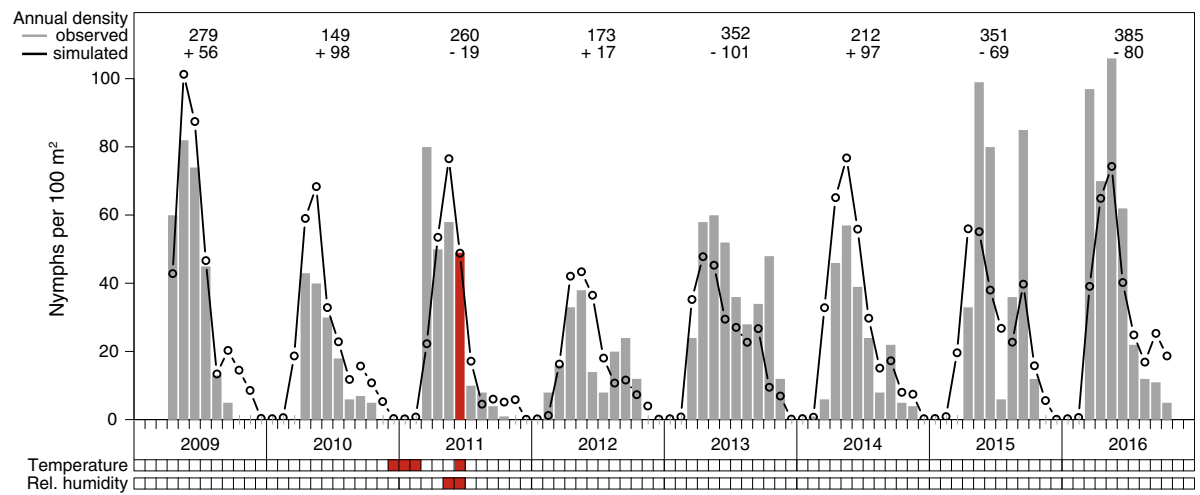

Fig. 3 Monthly nymphal tick density in Haselmühl (Germany) between 2009 and 2016 (unit: nymphs per $100 \mathrm{~m}^{2}$ ). Observations are shown as grey bars and simulations as lines. To illustrate the climatic variables determining the density in May 2011, the mean temperature between November 2010 and January 2011 as well as the mean relative humidity from April to May 2011 are highlighted in red

as the inter-annual fluctuations reasonably well. Little to no activity was observed in the winter months, while the activity peaked in late spring, mainly in May. In some years, a secondary, but not so marked, peak was also documented in early autumn, mainly in September. The coefficient of determination $R^{2}$ indicated that a total of $64.8 \%$ of the variation in the observed nymphal density was explained by the model. Compared to the null model with exclusively climatic variables (not shown), the $R^{2}$ is $27 \%$ higher. The goodness-of-fit was evaluated by a RMSE of 17 ticks per month.

A second model was developed to explain the mean monthly density of nymphal ticks. In order to assess the question which variables define the seasonal cycle, the procedure described above was repeated. The mean monthly density was described using only the month-to-month temperature $\mathrm{T}(0,0)$, the averaged relative humidity of the month of the flagging event and 1 month previously $\mathrm{rH}(1,0)$, and the four seasons as categorical

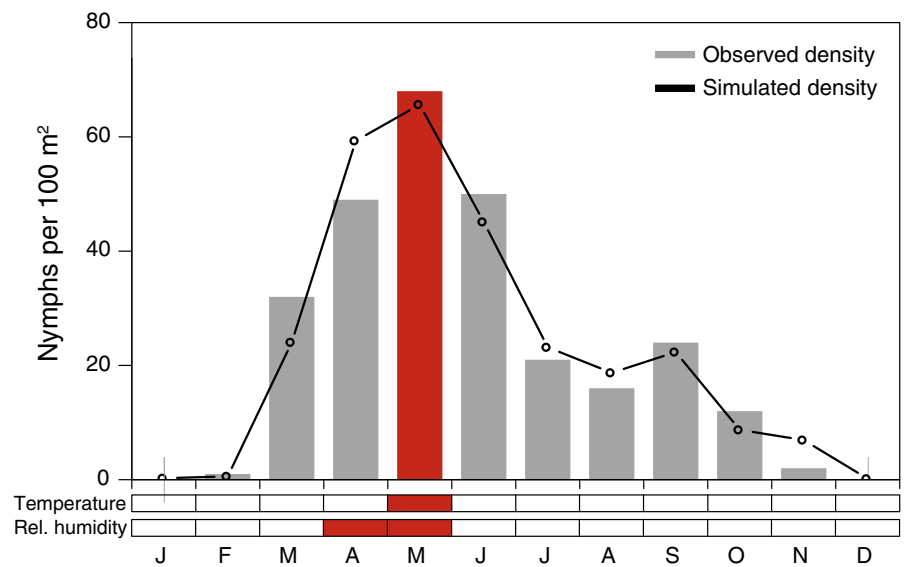

Fig. 4 Mean monthly nymphal tick density in Haselmühl (Germany). Observations are shown as grey bars and simulations as lines. To illustrate the climatic variables determining the density in May, the mean temperature in May as well as the mean relative humidity from April to May are highlighted in red 
variables (Table 1, Fig. 4). A marked higher $R^{2}$ of $95.6 \%$ and a goodness-of-fit of RMSE of 5 ticks per month were calculated. Compared to the mean peak tick density of about 70 ticks per $100 \mathrm{~m}^{2}$ this error is extremely low.

\section{Discussion}

A time series of monthly questing nymphal I. ricinus flagged in Haselmühl (Germany) over a period of eight consecutive years was presented. The length of this time series is unique for Germany. Comparable or longer time series have been published for e.g. I. scapularis with 8 (Schulze et al. 2009), 14 (Berger et al. 2014) or 25 years (Hayes et al. 2015), but with markedly lower flagging intervals and occasional gaps between sampling years. However, for quantitative statements, e.g. regarding the impact of climate change on tick densities, longer periods are needed. Basically, several methods are available for monitoring tick activity: flagging/dragging (Estrada-Peña et al. 2013), collecting from small mammals (Pfäffle et al. 2011), or monitoring on field plots (Dautel et al. 2008). All methods and their variations have advantages and disadvantages as discussed by Dobson (2013) or Mays et al. (2016). Nevertheless, the flagging method gives the best insights into long-term tick population dynamics and activity. Although flagging is the most common method, it is always a snapshot of the current situation influenced by environmental variables (Dantas-Torres et al. 2013). It will, therefore, be a challenge for the future to compile time series of up to 30 or more consecutive years of standardized tick sampling to improve our understanding of the influence of climate and environmental change on tick densities.

Here, cross correlation maps (CCMs) were introduced to identify time-lagged and interval-averaged associations between ticks and environmental variables. CCMs, primarily used for insects with multiple-generations per year, were applied for the first time to tick densities. For both the inter-annual and the seasonal cycle, temperature and relative humidity with different time lags were revealed as the determining environmental variables for nymphal tick densities. The diapause (survival, inactivity) and questing (activity, ability to find host, survival) are principally affected by both variables. Contrary, the development (rate and duration, emergence) is mainly influenced by temperature (Ostfeld and Brunner 2015). Here, the mean temperature in the month of the flagging event and the mean relative humidity of the actual month and the previous one are particularly important for both temporal scales. In addition, for the inter-annual tick density of the complete time series (model I), the temperature mean of 4-6 months prior to flagging is required for an optimal model fit. The environmental variables such as the temperature in May, the temperature mean from November to January ( 3 months) and the relative humidity mean from April to May (2 months) prior to flagging determine the first activity maximum in May (as marked in red in Fig. 3).

The seasonal and inter-annual variability of the nymphal tick density was also found to be affected by the abundance of hosts. Cayol et al. (2017) demonstrated that the abundance of rodent species is positively correlated with those of I. ricinus larvae and nymphs. For Germany, several time series were compiled e.g. for field voles (Microtus agrestis) or bank voles (Myodes glareolus) some of which go back to 1952 (Imholt et al. 2017). However, these vole data were not used in the current study, as the observation periods available for the voles did not match those of the ticks. Instead of voles, time series of the European hare (Lepus europaeus) were compiled from hunting statistics and shown to improve the model 
fit. The hunted hares were determined to be positively, but marginally, correlated with the nymphal tick densities in the following year. Although the role of hares in the transmission of pathogens, e.g. TBE virus (Palo 2014), is unclear, they are assumed to act as a reservoir or as transport hosts for ticks (Tälleklint and Jaenson 1993). The hunting statistics can be interpreted as in place of not yet determined factors such as small rodent density. Alternatively, rodent density may be estimated from beech mast data of the previous year. As demonstrated by Clement et al. (2009) and Reil et al. (2015), a year with abundant fructification is followed by a year with high rodent density, the main blood hosts for larvae (Matuschka et al. 1991). However, this approach revealed no significant improvement of both models.

Overall, this study demonstrated that using CCMs to identify time-lagged correlations enables quantitative seasonal predictions of nymphal tick densities to be made. The time lags and averaging intervals presented here should be generally applicable, at least in a crude approximation. This conclusion is supported by a first application of CCMs (not shown) using the I. ricinus time series collected in Prague (Czech Republic) by Daniel et al. (2015). The parameters for the two predictive models, however, must be appropriate for each new location. Furthermore, CCMs may be an elegant method to find optimal relationships between tick activity and the occurrence of human TBE cases. Without using CCMs, Daniel et al. (2010) found maximal correlations between TBE cases and the $I$. ricinus abundance 6 weeks ago, and a 1-month time lag was empirically estimated by Randolph et al. (2008). Such predictions are essential for epidemiological considerations: not only for individuals at risk of acquiring a pathogen capable of causing TBE or LB, but also for (veterinary) public health authorities.

Acknowledgements Open access funding provided by University of Veterinary Medicine Vienna. The study was supported in part by a German Center of Infection Research (DZIF) grant. The funders had no role in study design, data collection and analysis, decision to publish, or preparation of the manuscript. The authors would like to thank Clair Firth for English language editing and an anonymous reviewer for his valuable hints.

Open Access This article is distributed under the terms of the Creative Commons Attribution 4.0 International License (http://creativecommons.org/licenses/by/4.0/), which permits unrestricted use, distribution, and reproduction in any medium, provided you give appropriate credit to the original author(s) and the source, provide a link to the Creative Commons license, and indicate if changes were made.

\section{References}

Akaike H (1974) A new look at the statistical model identification. IEEE Trans Automat Control 19:716-723. https://doi.org/10.1007/978-1-4612-1694-0_16

Alonso-Carné J, García-Martín A, Estrada-Peña A (2016) Modelling the phenological relationships of questing immature Ixodes ricinus (Ixodidae) using temperature and NDVI data. Zoonoses Public Health 63:40-52. https://doi.org/10.1111/zph.12203

Barandika J, Berriatua E, Barral M, Juste R, Anda P, García-Pérez A (2006) Risk factors associated with ixodid tick species distributions in the Basque region in Spain. Med Vet Entomol 20:177-188. https:// doi.org/10.1111/j.1365-2915.2006.00619.x

Berger KA, Ginsberg HS, Dugas KD, Hamel LH, Mather TN (2014) Adverse moisture events predict seasonal abundance of Lyme disease vector ticks (Ixodes scapularis). Parasit Vectors 7:181. https://doi. org/10.1186/1756-3305-7-181

Boehnke D, Brugger K, Pfäffle M, Sebastian P, Norra S, Petney T, Oehme R, Littwin N, Lebl K, Raith J, Walter M, Gebhardt R, Rubel F (2015) Estimating Ixodes ricinus densities on the landscape scale. Int J Health Geogr 14:23. https://doi.org/10.1186/s12942-015-0015-7 
Bronner A, Morignat E, Hénaux V, Madouasse A, Gay E, Calavas D (2015) Devising an indicator to detect mid-term abortions in dairy cattle: a first step towards syndromic surveillance of abortive diseases. PLoS ONE 10(e0119):012. https://doi.org/10.1371/journal.pone.0119012

Brugger K, Rubel F (2013) Bluetongue disease risk assessment based on observed and projected Culicoides obsoletus spp. vector densities. PLoS ONE 8(e60):330. https://doi.org/10.1371/journal.pone.0060330

Brugger K, Boehnke D, Petney T, Dobler G, Pfeffer M, Silaghi C, Schaub GA, Pinior B, Dautel H, Kahl O, Pfister K, Süss J, Rubel F (2016) A density map of the tick-borne encephalitis and Lyme borreliosis vector Ixodes ricinus (Acari: Ixodidae) for Germany. J Med Entomol 53:1292-1302. https://doi.org/10. 1093/jme/tjw116

Cat J, Beugnet F, Hoch T, Jongejan F, Prangé A, Chalvet-Monfray K (2017) Influence of the spatial heterogeneity in tick abundance in the modeling of the seasonal activity of Ixodes ricinus nymphs in Western Europe. Exp App Acarol 71:115-130. https://doi.org/10.1007/s10493-016-0099-1

Cayol C, Koskela E, Mappes T, Siukkola A, Kallio ER (2017) Temporal dynamics of the tick Ixodes ricinus in northern Europe: epidemiological implications. Parasit Vectors 10:166. https://doi.org/10.1186/ s13071-017-2112-X

Chuang TW, Ionides EL, Knepper RG, Stanuszek WW, Walker ED, Wilson ML (2012) Cross-correlation map analyses show weather variation influences on mosquito abundance patterns in Saginaw County, Michigan, 1989-2005. J Med Entomol 49:851-858. https://doi.org/10.1603/me11150

Clement J, Vercauteren J, Verstraeten WW, Ducoffre G, Barrios JM, Vandamme AM, Maes P, Van Ranst M (2009) Relating increasing hantavirus incidences to the changing climate: the mast connection. Int J Health Geogr 8:1. https://doi.org/10.1186/1476-072X-8-1

Curriero FC, Shone SM, Glass GE (2005) Cross correlation maps: a tool for visualizing and modeling time lagged associations. Vector Borne Zoonotic Dis 5:267-275. https://doi.org/10.1089/vbz.2005.5.267

Daniel M, Vráblk T, Valter J, Křiž B, Danielová V (2010) The TICKPRO computer program for predicting Ixodes ricinus host-seeking activity and the warning system published on websites. Cent Eur J Public Health 18:230-236

Daniel M, Malý M, Danielová V, BížB Křiž, Nuttall P (2015) Abiotic predictors and annual seasonal dynamics of Ixodes ricinus, the major disease vector of Central Europe. Parasit Vectors 8:478. https:// doi.org/10.1186/s13071-015-1092-y

Dantas-Torres F, Lia RP, Capelli G, Otranto D (2013) Efficiency of flagging and dragging for tick collection. Exp Appl Acarol 61:119-127. https://doi.org/10.1007/s10493-013-9671-0

Dautel H, Dippel C, Kämmer D, Werkhausen A, Kahl O (2008) Winter activity of Ixodes ricinus in a Berlin forest. Int J Med Microbiol 298(Suppl 1):50-54. https://doi.org/10.1016/j.ijmm.2008.01.010

Diarra M, Fall M, Lancelot R, Diop A, Fall AG, Dicko A, Seck MT, Garros C, Allène X, Rakotoarivony I, Bakhoum MT, Bouyer J, Guis H (2015) Modelling the abundances of two major Culicoides (Diptera: Ceratopogonidae) species in the Niayes area of Senegal. PLoS ONE 10(e0131):021. https://doi.org/10. 1371/journal.pone.0131021

Dobler G, Gniel D, Petermann R, Pfeffer M (2012) Epidemiology and distribution of tick-borne encephalitis. Wien Med Wochenschr 162:230-238. https://doi.org/10.1007/s10354-012-0100-5

Dobson ADM (2013) Ticks in the wrong boxes: assessing error in blanket-drag studies due to occasional sampling. Parasit Vectors 6:344. https://doi.org/10.1186/1756-3305-6-344

Estrada-Peña A, Gray J, Kahl O, Lane R, Nijhof A (2013) Research on the ecology of ticks and tick-borne pathogens-methodological principles and caveats. Front Cell Infect Microbiol 3:29. https://doi.org/ 10.3389/fcimb.2013.00029

German Weather Service (2017) Climate data Germany. http://www.dwd.de/DE/leistungen/ klimadatendeutschland/klimadatendeutschland.html. Last accessed 01 June 2017

Gray J (1981) The fecundity of Ixodes ricinus (L.) (Acarina: Ixodidae) and the mortality of its developmental stages under field conditions. Bull Entomol Res 71:533-542. https://doi.org/10.1017/ s0007485300008543

Gray JS (1998) The ecology of ticks transmitting Lyme borreliosis. Exp Appl Acarol 22:249-258. https:// doi.org/10.1023/A:1006070416135

Gray JS, Kahl O, Lane RS, Levind ML, Tsaoe JI (2016) Diapause in ticks of the medically important Ixodes ricinus species complex. Ticks Tick-Borne Dis 7:992-1003. https://doi.org/10.1016/j.ttbdis.2016.05. 006

Groen TA, L'Ambert G, Bellini R, Chaskopoulou A, Petric D, Zgomba M, Marrama L, Bicout DJ (2017) Ecology of West Nile virus across four European countries: empirical modelling of the Culex pipiens abundance dynamics as a function of weather. Parasit Vectors 10:524. https://doi.org/10.1186/s13071$017-2484-y$ 
Hayes LE, Scott JA, Stafford KC (2015) Influences of weather on Ixodes scapularis nymphal densities at long-term study sites in Connecticut. Ticks Tick-Borne Dis 6:258-266. https://doi.org/10.1016/j.ttbdis. 2015.01.006

Hillyard P (1996) Ticks of north-west Europe: keys and notes for identification of the species. Linnaean Society, London

Imholt C, Reil D, Plašil P, Rödiger K, Jacob J (2017) Long-term population patterns of rodents and associated damage in German forestry. Pest Manag Sci 73:332-340. https://doi.org/10.1002/ps.4325

Kazimírová M, Hamšíková Z, Kocianová E, Marini G, Mojšová M, Mahríková L, Berthová L, Slovák M, Rosá R (2016) Relative density of host-seeking ticks in different habitat types of south-western Slovakia. Exp Appl Acarol 69:205-224. https://doi.org/10.1007/s10493-016-0025-6

Kiewra D, Kryza M, Szymanowski M (2014) Influence of selected meteorological variables on the questing activity of Ixodes ricinus ticks in Lower Silesia, SW Poland. J Vec Ecol 39:138-145. https://doi.org/10. 1111/j.1948-7134.2014.12080.x

Kottek M, Grieser J, Beck C, Rudolf B, Rubel F (2006) World map of the Köppen-Geiger climate classification updated. Meteorol Z 15:259-263. https://doi.org/10.1127/0941-2948/2006/0130

Kunze U, The ISW-TBE (2016) Tick-borne encephalitis-still on the map: report of the 18th annual meeting of the international scientific working group on tick-borne encephalitis (ISW-TBE). Ticks Tick-Borne Dis 7:911-914. https://doi.org/10.1016/j.ttbdis.2016.04.009

Lebl K, Brugger K, Rubel F (2013) Predicting Culex pipiens/restuans population dynamics by interval lagged weather data. Parasit Vectors 6:129. https://doi.org/10.1186/1756-3305-6-129

Li S, Heyman P, Cochez C, Simons L, Vanwambeke SO (2012) A multi-level analysis of the relationship between environmental factors and questing Ixodes ricinus dynamics in Belgium. Parasit Vectors 5:149. https://doi.org/10.1186/1756-3305-5-149

Lockaby G, Noori N, Morse W, Zipperer W, Kalin L, Governo R, Sawant R, Ricker M (2016) Climatic, ecological, and socioeconomic factors associated with West Nile virus incidence in Atlanta, Georgia, U.S.A. J Vec Ecol 41:232-243. https://doi.org/10.1111/jvec.12218

Matuschka FR, Fischer P, Musgrave K, Richter D, Spielman A (1991) Hosts on which nymphal Ixodes ricinus most abundantly feed. Am J Trop Med Hyg 44:100-107. https://doi.org/10.4269/ajtmh.1991. 44.100

Mays SE, Houston AE, Trout Fryxell RT (2016) Comparison of novel and conventional methods of trapping ixodid ticks in the southeastern U.S.A. Med Vet Entomol 30:123-134. https://doi.org/10.1111/mve. 12160

Mihalca AD, Sándor AD (2013) The role of rodents in the ecology of Ixodes ricinus and associated pathogens in Central and Eastern Europe. Front Cell Infect Microbiol 3:56. https://doi.org/10.3389/ fcimb.2013.00056

Norman RA, Worton AJ, Gilbert L (2016) Past and future perspectives on mathematical models of tickborne pathogens. Parasitology 143:850-859. https://doi.org/10.1017/S0031182015001523

Osipova T, Grigoryeva L, Samoylova E, Shapar A, Bychkova E (2017) The influence of meteorological factors on the activity of adult taiga ticks (Ixodes persulcatus Sch., Ixodinae) in St. Petersburg and its environs. Entomol Rev 97:554-563. https://doi.org/10.1134/S0013873817040169

Ostfeld RS, Brunner JL (2015) Climate change and Ixodes tick-borne diseases of humans. Philos Trans R Soc Lond B Biol Sci. https://doi.org/10.1098/rstb.2014.0051

Palo RT (2014) Tick-borne encephalitis transmission risk: Its dependence on host population dynamics and climate effects. Vector Borne Zoonotic Dis 14:346-352. https://doi.org/10.1089/vbz.2013.1386

Perret JL, Guigoz E, Rais O, Gern L (2000) Influence of saturation deficit and temperature on Ixodes ricinus tick questing activity in a Lyme borreliosis-endemic area (Switzerland). Parasitol Res 86:554-557. https://doi.org/10.1007/s004360000209

Pfäffle M, Petney T, Skuballa J, Taraschewski H (2011) Comparative population dynamics of a generalist (Ixodes ricinus) and specialist tick (I. hexagonus) species from European hedgehogs. Exp Appl Acarol 54:151-164. https://doi.org/10.1007/s10493-011-9432-x

Randolph SE, Asokliene L, Avsic-Zupanc T, Bormane A, Burri C, Gern L, Golovljova I, Hubalek Z, Knap N, Kondrusik M, Kupca A, Pejcoch M, Vasilenko V, žygutiene M (2008) Variable spikes in tick-borne encephalitis incidence in 2006 independent of variable tick abundance but related to weather. Parasit Vectors 1:44. https://doi.org/10.1186/1756-3305-1-44

R Development Core Team (2017) R: a language and environment for statistical computing, R Foundation for Statistical Computing, Vienna, Austria, ISBN 3-900051-07-0. Version 3.3.1. http://www.R-project. org/

Reil D, Imholt C, Eccard JA, Jacob J (2015) Beech fructification and bank vole population dynamicscombined analyses of promoters of human puumala virus infections in Germany. PLoS ONE 10(e0134):124. https://doi.org/10.1371/journal.pone.0134124 
Rizzoli A, Hauffe HC, Tagliapietra V, Neteler M, Ros R (2009) Forest structure and roe deer abundance predict tick-borne encephalitis risk in Italy. PLoS ONE 4:e4336. https://doi.org/10.1371/journal.pone. 0004336

Rubel F, Brugger K, Monazahian M, Habedank B, Dautel H, Leverenz S, Kahl O (2014) The first German map of georeferenced ixodid tick locations. Parasit Vectors 7:477. https://doi.org/10.1186/s13071-0140477-7

Rubel F, Brugger K, Haslinger K, Auer I (2017) The climate of the European Alps: shift of very high resolution Köppen-Geiger climate zones 1800-2100. Meteorol Z 26:115-125. https://doi.org/10.1127/ metz/2016/0816

Schulz M, Mahling M, Pfister K (2014) Abundance and seasonal activity of questing Ixodes ricinus ticks in their natural habitats in southern Germany in 2011. J Vec Ecol 39:56-65. https://doi.org/10.1111/j. 1948-7134.2014.12070.x

Schulze TL, Jordan RA, Schulze CJ, Hung RW (2009) Precipitation and temperature as predictors of the local abundance of Ixodes scapularis (Acari: Ixodidae) nymphs. J Med Entomol 46:1025-1029. https:// doi.org/10.1603/033.046.0508

Shone SM, Curriero FC, Lesser CR, Glass GE (2006) Characterizing population dynamics of Aedes sollicitans (Diptera: Culicidae) using meteorological data. J Med Entomol 43:393-402. https://doi.org/10. 1093/jmedent/43.2.393

Stanek G, Wormser GP, Gray J, Strle F (2012) Lyme borreliosis. The Lancet 379:461-473. https://doi.org/ 10.1016/s0140-6736(11)60103-7

Stoddard ST, Wearing HJ, Reiner RC Jr, Morrison AC, Astete H, Vilcarromero S, Alvarez C, Ramal-Asayag C, Sihuincha M, Rocha C, Halsey ES, Scott TW, Kochel TJ, Forshey BM (2014) Long-term and seasonal dynamics of dengue in Iquitos, Peru. PLoS Negl Trop Dis 8:e3003. https://doi.org/10.1371/ journal.pntd.0003003

Tälleklint L, Jaenson TG (1993) Maintenance by hares of European Borrelia burgdorferi in ecosystems without rodents. J Med Entomol 30:273-276. https://doi.org/10.1093/jmedent/30.1.273

Taylor DB, Berkebile DR (2011) Phenology of stable fly (Diptera: Muscidae) larvae in round bale hay feeding sites in eastern Nebraska. J Med Entomol 40:184-193. https://doi.org/10.1603/en10245

Taylor DB, Berkebile DR, Scholl PJ (2007) Stable fly population dynamics in eastern Nebraska in relation to climatic variables. J Med Entomol 44:765-771. https://doi.org/10.1093/jmedent/44.5.765

Vollack K, Sodoudi S, Névir P, Müller K, Richter D (2017) Influence of meteorological parameters during the preceding fall and winter on the questing activity of nymphal Ixodes ricinus ticks. Int J Biometeorol 61:1787-1795. https://doi.org/10.1007/s00484-017-1362-9

Walsh AS, Glass GE, Lesser CR, Curriero FC (2008) Predicting seasonal abundance of mosquitoes based on off-season meteorological conditions. Environ Ecol Stat 15:279-291. https://doi.org/10.1007/s10651007-0056-6

Weidmann M, Frey S, Freire CCM, Essbauer S, Růžek D, Klempa B, Zubrikova D, Vögerl M, Pfeffer M, Hufert FT, Zanotto PM, Dobler G (2013) Molecular phylogeography of tick-borne encephalitis virus in central Europe. J Gen Virol 94:2129-2139. https://doi.org/10.1099/vir.0.054478-0

World Meteorological Organization (2008) Guide to meteorological instruments and methods of observation. WMO-No. 8

Zhang D (2016) RSQ: coefficient of determination. R package version 6

Zhang D (2017) A coefficient of determination for generalized linear models. Am Stat. https://doi.org/10. 1080/00031305.2016.1256839

Zuur AF, Ieno E, Walker N, Saveliev A, Smith G (2009) Mixed effects models and extentions in ecology with R. Statistics for biology and health. Springer, New York 